\title{
High Mechanical Functionalization of Metallic Biomaterials through Thermomechanical Treatments*
}

\author{
Toshikazu AKAHORI**, Mitsuo NIINOMI**, Masaaki NAKAI** \\ and Harumi TSUTSUMI** \\ **Institute of Materials Research, Tohoku University, \\ 2-1-1 Katahira, Aoba-ku, Sendai 980-8587, Japan \\ Email: akahori@imr.tohoku.ac.jp
}

\begin{abstract}
Currently, $\beta$-type Ti-Nb-Ta-Zr alloys are gaining attention owing to their feasibility for use as biomedical materials. However, the deformation behaviors of these alloys have not yet been clarified. In this study, the $\mathrm{Nb}$ content of the Ti-30Nb-10Ta-5Zr (TNTZ) alloy was altered between 1.0 and 3.0 mass $\%$ from $30 \mathrm{mass} \%$, and the corresponding changes in the superelasticity and shape-memory characteristics were investigated by tensile loading-unloading tests, X-ray diffraction (XRD) analysis, and microstructural analysis using a transmission electron microscopy (TEM). When the $\mathrm{Nb}$ content is less than approximately 29 mass\%, the loading-unloading stress-strain curves show two-step gradients and are similar to those of common shape-memory alloys such as Ti-Ni alloys; these gradients result from stress-induced martensitic transformation and its reversion. When the $\mathrm{Nb}$ content is approximately 30 mass \%, the tensile loading-unloading curves show a nonlinear gradient corresponding to superelastic behavior, which can not be explained by XRD and TEM microstructural analyses on stress-induced martensitic transformation and its reversion in the present state. When the $\mathrm{Nb}$ content is approximately 31 mass $\%$, the tensile loading-unloading curves show a single gradient. The elastic deformation is mainly caused by the elastic strain in the lattice. Changes in the chemical content of $\mathrm{Nb}$ in TNTZ within a very narrow range are found to alter the superelastic behavior of this alloy.
\end{abstract}

Keywords: $\beta$-Type Titanium Alloy, Metallic Biomaterial, Stress-Induced Martensite, Elastic Deformation, Superelastic Behavior

\section{Introduction}

Titanium and its alloys have been widely used in structural biomaterials such as artificial hip joints and dental implants owing to their excellent specific strength and corrosion resistance. Initially, titanium alloys designed for use as general structural materials, such as Ti-6Al-4V ELI (extra low interstitial), were used as structural biomaterials. However, these general titanium alloys contain toxic elements such as $\mathrm{V}$ and hence cause serious health problems ${ }^{(1)}$. Therefore, new titanium alloys such as Ti-Nb-Ta-Zr alloys $^{(2)(3)}$, which comprise nontoxic and allergic-free alloying elements such as $\mathrm{Nb}$, Ta, and $\mathrm{Zr}$ have been developed for use as next-generation biomaterials.

The authors have developed a Ti-29Nb-13Ta-4.6Zr alloy, which is a $\beta$-type titanium 
alloy with a low elastic modulus, for biomedical applications ${ }^{(4)(5)}$. This alloy has excellent mechanical and biological properties, and is expected to be one of the important next-generation metallic biomaterials. Recently, the authors have found that this alloy exhibits superelastic behavior ${ }^{(6)}$, which is advantageous for the manufacture of stents, catheter guide wires, and orthodontic wires. However, they found that even a small change in the chemical composition of this alloy can alter its superelastic behavior. In this study, the authors varied the $\mathrm{Nb}$ content of the Ti-30Nb-10Ta-5Zr alloy, which has simplified the chemical composition of $\beta$-type Ti-29Nb-13Ta-4.6Zr alloy for biomedical applications developed by this authors, between 1.0 and 3.0 mass $\%$ from 30 mass $\%$. They also investigated the corresponding changes in the superelasticity and shape-memory effect characteristics of the alloy by tensile loading-unloading tests, X-ray diffraction (XRD) analysis, and transmission electron microscopy (TEM).

\section{Experimental Procedures}

\subsection{Material}

The basic chemical composition of the titanium alloy was considered to be Ti-30Nb-10Ta-5Zr. Only the $\mathrm{Nb}$ content of the alloy was varied from 30 mass $\%$ to 31, 29, 28, and 27 mass\%. Ingots of titanium alloys of different chemical compositions-Ti-31Nb-10Ta-5Zr, Ti-30Nb-10Ta-5Zr, Ti-29Nb-10Ta-5Zr, Ti-28Nb-10Ta-5Zr, and Ti-27Nb-10Ta-5Zr — were fabricated in a tri-arc furnace in an argon atmosphere. The length, width, and thickness of the prepared ingots were approximately 50 $\mathrm{mm}, 25 \mathrm{~mm}$, and $10 \mathrm{~mm}$, respectively. Each ingot was homogenized at $1273 \mathrm{~K}$ for $21.6 \mathrm{ks}$ and then quenched in water. Each homogenized ingot was then cold-rolled at a reduction ratio of around $85 \%$ to form a $1.5-\mathrm{mm}$-thick plate. Each plate was subjected to solution treatment at $1123 \mathrm{~K}$ for $1.8 \mathrm{ks}$ and subsequent air cooling.

Small specimens weighing $2.0 \mathrm{~g}$ were machined from two parts of the plate of each alloy and used for analyzing the true chemical composition of the respective alloys. Each specimen was polished using waterproof emery papers with a grid size of up to 1500 . The chemical composition of each specimen was analyzed by inductively coupled plasma (ICP) spectrometry. Table 1 shows the chemical composition of each alloy. The $\mathrm{Nb}, \mathrm{Ta}$, and $\mathrm{Zr}$ contents of each alloy varied from 0.1 to $0.3 \mathrm{mass} \%, 0.08$ to $0.4 \mathrm{mass} \%$, and 0.09 to $0.12 \mathrm{mass} \%$, respectively, than each nominal value. Hereafter, each alloy will be indicated by its corresponding true $\mathrm{Nb}$ content, i.e., $31.0 \mathrm{Nb}, 30.3 \mathrm{Nb}(30.1 \mathrm{Nb}), 28.7 \mathrm{Nb}, 27.9 \mathrm{Nb}$, and $27.2 \mathrm{Nb}$.

Table 1 Chemical compositions of Ti-XNb-10Ta-5Zr alloys.

\begin{tabular}{cccccc}
\hline Sample & $\mathrm{Nb}$ & $\mathrm{Ta}$ & $\mathrm{Zr}$ & $\mathrm{O}$ & $\mathrm{Ti}$ \\
\hline Ti-27Nb-10Ta-5Zr alloy & 27.2 & 9.92 & 5.06 & 0.08 & bal. \\
Ti-28Nb-10Ta-5Zr alloy & 27.9 & 10.4 & 4.92 & 0.08 & bal. \\
Ti-29Nb-10Ta-5Zr alloy & 28.7 & 10.1 & 5.12 & 0.08 & bal. \\
Ti-30Nb-10Ta-5Zr alloy* & 30.3 & 10.2 & 4.91 & 0.08 & bal. \\
& $(30.1)$ & $(9.99)$ & $(4.99)$ & $(0.08)$ & (bal.) \\
Ti-31Nb-10Ta-5Zr alloy & 31.0 & 10.3 & 5.09 & 0.08 & bal. \\
\hline
\end{tabular}

*Both tensile properties, tensile deformation behaviors and microstructures of Ti-30Nb-10Ta-5Zr alloys with slightly differences of $\mathrm{Nb}, \mathrm{Ta}$ and $\mathrm{Zr}$ contents were almost similar.

\subsection{Mechanical Tests}

For tensile loading-unloading tests, tensile specimens whose gauge length, width, and thickness were $15 \mathrm{~mm}, 3 \mathrm{~mm}$, and $1.5 \mathrm{~mm}$, respectively, were machined from the 
corresponding alloy plates with a milling machine. The surface of each tensile specimen was polished using waterproof emery papers with a grid size of up to 1500 . The tensile loading-unloading tests were carried out in air at $300 \mathrm{~K}$ (room temperature), $253 \mathrm{~K}$, and 213 $\mathrm{K}$ using an Instron-type machine with a capacity of $20 \mathrm{kN}$ and a crosshead speed of $8.33 \times$ $10^{-6} \mathrm{~m} / \mathrm{s}$. The load was detected using a load cell attached to the machine, and the strain was measured using a thin foil gauge attached directly to the specimen, which was convert the total strain (\%) of specimen by change in the resistance of that during the deformation with a dynamic strain indicator. Loading and unloading cycles were repeated at $0.5 \%$ strain intervals up to a total strain of $4.0 \%$. The maximum elastic strain from which was subtracted the plastic strain is defined as the recovered strain estimated form the loading and unloading curve up to $4.0 \%$. The elastic moduli of specimens (length: $40 \mathrm{~mm}$; width: 5 $\mathrm{mm}$; thickness: $1.5 \mathrm{~mm}$ ) machined from the alloy plates were measured at room temperature in air; the measurements were made using an elastic modulus-measuring device via the free resonance method.

\subsection{Evaluation of Microstructures}

An optical microscope was used to carry out microstructural observations on rectangular specimens (dimensions: $5.0 \times 5.0 \times 1.5 \mathrm{~mm}^{3}$ ) machined from the alloy plates and on the gauge section of the specimens of each alloy subjected to tensile loading-unloading tests. Microstructural observations of the thin foil specimens were carried out by transmission electron microscopy (TEM) at an accelerating voltage of $200 \mathrm{kV}$; these specimens were prepared from disk-shaped specimens that were cut out from immediately beneath the fracture surface of the specimens subjected to the loading-unloading testes.

The constituent phases of the specimens were identified by performing X-ray diffraction (XRD) analyses at $300 \mathrm{~K}, 143 \mathrm{~K}$, and $93 \mathrm{~K}$ using $\mathrm{Cu}-\mathrm{K} \alpha$ radiation (tube electric current: 30 $\mathrm{mA}$; tube voltage: $40 \mathrm{kV}$ ) at scanning angles of $30^{\circ}-80^{\circ}$; for the $\mathrm{XRD}$ analysis, plate-type specimens (length: $10 \mathrm{~mm}$; width: $5 \mathrm{~mm}$; thickness: $1.5 \mathrm{~mm}$ ) were machined out from the alloy plates and polished using waterproof emery paper with a grid size of up to 1500 .

XRD analysis under tensile loading conditions was performed using tensile loading-unloading specimens (gauge length: $10 \mathrm{~mm}$; width: $2.5 \mathrm{~mm}$; thickness: $0.5 \mathrm{~mm}$ ) that were machined from the alloy plates and polished using waterproof emery paper with a grid size of up to 1500. Each specimen was attached to the tensile jig, which was set in the sample chamber of the XRD apparatus. Tensile loading and unloading were carried out manually under an applied tensile strain of $0-3.0 \%$.

\section{Results and discussion}

\subsection{Microstructure}

Figure 1 shows the optical microstructures of $27.2 \mathrm{Nb}, 27.9 \mathrm{Nb}, 28.7 \mathrm{Nb}, 30.3 \mathrm{Nb}$, and $31.0 \mathrm{Nb}$. The microstructure of each alloy revealed the presence of equiaxed $\beta$ grains with diameters ranging from 13 to $18 \mu \mathrm{m}$. The diameter of these equiaxed $\beta$ grains does not show any drastic change even when the $\mathrm{Nb}$ content in the alloy was increased from 27.2 to 31.0 mass $\%$.

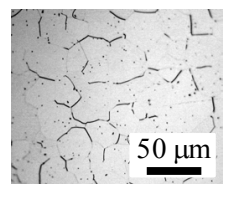

(a) $27.2 \mathrm{Nb}$

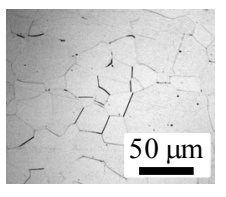

(b) $27.9 \mathrm{Nb}$

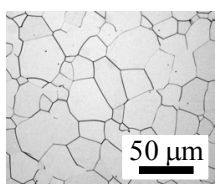

(c) $28.7 \mathrm{Nb}$

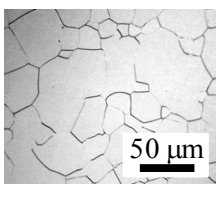

(d) $30.3 \mathrm{Nb}$

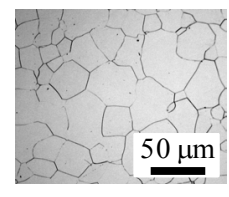

(e) $31.0 \mathrm{Nb}$

Fig. 1 Optical micrographs of (a) $27.2 \mathrm{Nb}$, (b) $27.9 \mathrm{Nb}$, (c) $28.7 \mathrm{Nb}$, (d) $30.3 \mathrm{Nb}$ and (e) $31.0 \mathrm{Nb}$. 
XRD patterns of $31.0 \mathrm{Nb}, 30.3 \mathrm{Nb}, 28.7 \mathrm{Nb}$, and $27.9 \mathrm{Nb}$ show peaks due to the $\beta$-phase only;

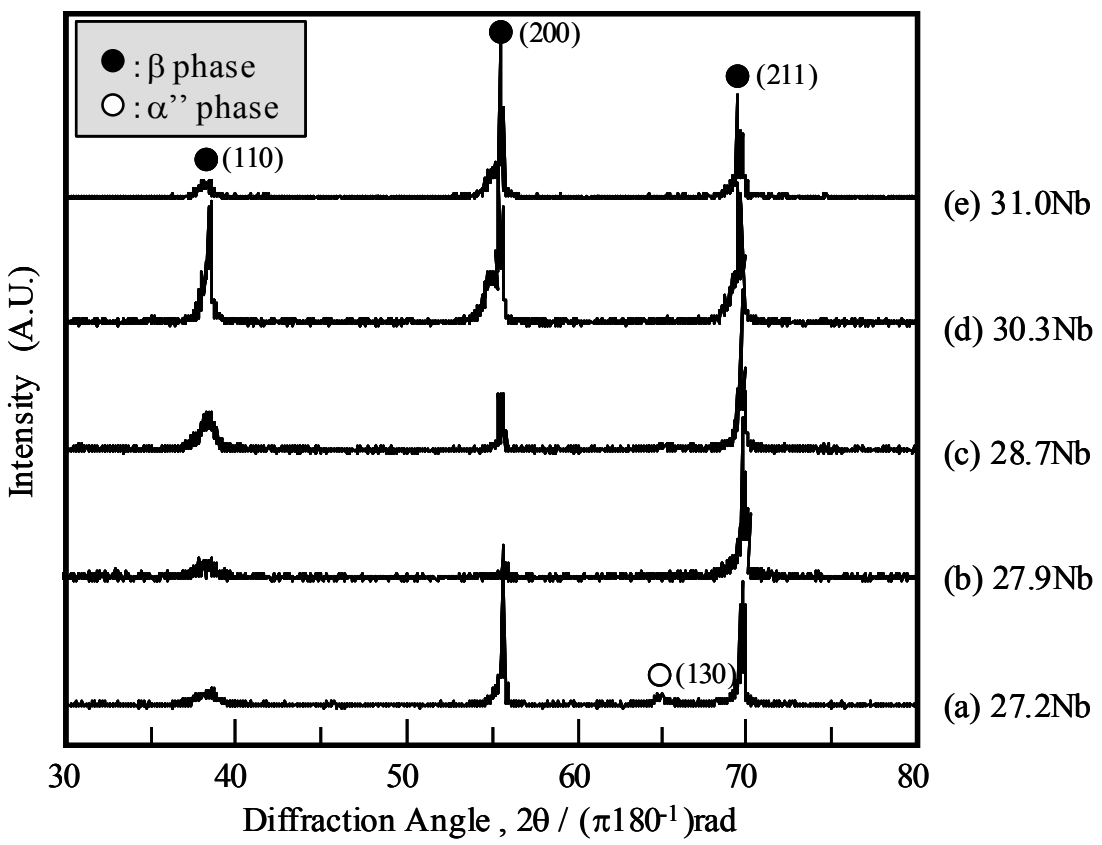

Fig. 2 XRD profiles of (a) $27.2 \mathrm{Nb}$, (b) $27.9 \mathrm{Nb}$, (c) $28.7 \mathrm{Nb}$, (d) $30.3 \mathrm{Nb}$ and (e) $31.0 \mathrm{Nb}$ at $300 \mathrm{~K}$.

therefore, these are concluded to be single-phase alloys, which comprise only the $\beta$ phase. However, the XRD spectrum of $27.2 \mathrm{Nb}$ shows a very weak peak corresponding to the $\alpha$ " phase at a diffraction angle of around $66^{\circ}$ along with the peaks due to the $\beta$ phase. Therefore, $27.2 \mathrm{Nb}$ is thought to comprise both $\alpha$ " (martensite) and $\beta$ phases. The TEM microstructural analysis of $27.9 \mathrm{Nb}, 28.7 \mathrm{Nb}, 30.3 \mathrm{Nb}$, and $31.0 \mathrm{Nb}$ revealed the presence of a single $(\beta)$ phase, while that of $27.2 \mathrm{Nb}$ revealed that the $\beta$ phase was the main phase and that the $\alpha$ " and $\omega$ phases were formed occasionally. The results of TEM microstructural analysis were almost consistent with those of XRD analysis.

\subsection{Mechanical properties}

Figure 3 shows the tensile strength, $0.2 \%$ proof stress, elongation, and elastic moduli of $27.2 \mathrm{Nb}, 27.9 \mathrm{Nb}, 28.7 \mathrm{Nb}, 30.3 \mathrm{Nb}$, and $31.0 \mathrm{Nb}$ as functions of their respective $\mathrm{Nb}$ contents.

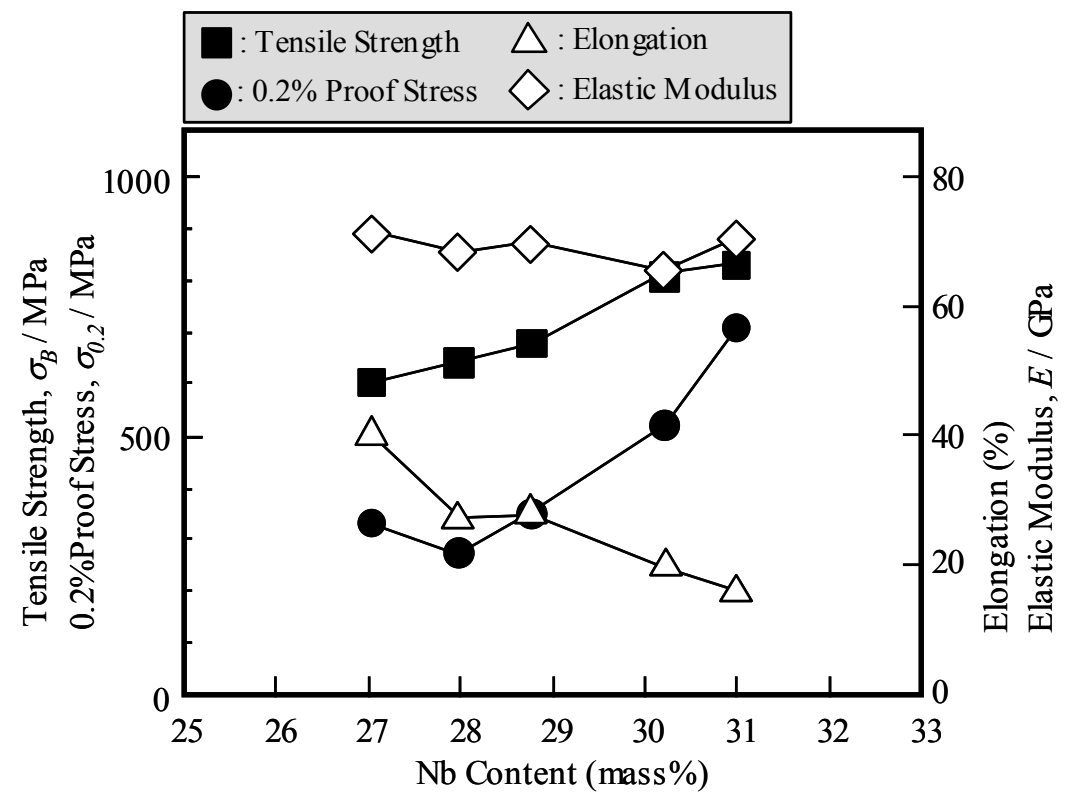

Fig. 3 Tensile propert ies and elastic modulus of Ti-XNb-10Ta-5Zr alloy at $300 \mathrm{~K}$ as a function of $\mathrm{Nb}$ content. 
With a decrease in the $\mathrm{Nb}$ content, the tensile strength and $0.2 \%$ proof stress decrease, while the elongation increases. The $0.2 \%$ proof stress decreases considerably at a $\mathrm{Nb}$ content of $27.9 \%$, and the elongation increases considerably at a $\mathrm{Nb}$ content of $27.2 \%$. In general, for $\beta$-type titanium alloys, in the unstable $\beta$-phase region, $\{332\}<113>$ twining, which is different from $\{112\}<111>$ twinning that generally occurs in bcc structures, is predominant during deformation ${ }^{(7)}$. The slip system acts in the more stable $\beta$ phase region. It has been reported that the deformation caused in the unstable $\beta$ phase region has a greater effect on the $\beta-\alpha$ " phase transformation than does the deformation caused in the region where $\{332\}<113>$ deformation twinning occurs. Therefore, in $27.2 \mathrm{Nb}$, the $\beta$ phase of which is considered to be the most unstable as compared with the $\beta$ phases of the other alloys, multiple deformation mechanisms such as stress-induced martensitic transformation, twinning, and slip may occur; because of this, $27.2 \mathrm{Nb}$ alloy shows the highest elongation among all the alloys studied herein. The elastic moduli of the alloys in this study are almost similar. The elastic modulus of $30.3 \mathrm{Nb}$ is the smallest $(65 \mathrm{GPa})$, while the elastic moduli of the other alloys are more or less $70 \mathrm{GPa}$. Small changes in the $\mathrm{Nb}$ content have no significant effect on the elastic modulus.

\subsection{Elastic Deformation Behavior at Room Temperature}

The tensile loading-unloading stress-strain curves of $27.2 \mathrm{Nb}, 27.9 \mathrm{Nb}, 28.7 \mathrm{Nb}, 30.3 \mathrm{Nb}$, and $31.0 \mathrm{Nb}$ are shown in Fig. 4 . In the case of $27.2 \mathrm{Nb}, 27.9 \mathrm{Nb}$, and $28.7 \mathrm{Nb}$, the stress increases with strain in a two-step manner, where the gradient of stress-strain curve changes from the first step to the second step as shown in Fig. 4(a), in the elastic (pseudoelastic) deformation region under the loading-unloading processes. The stress-strain curve exhibits stress hysteresis during loading and unloading. The maximum elastic strains for $27.2 \mathrm{Nb}$, $27.9 \mathrm{Nb}$, and $28.7 \mathrm{Nb}$ are $1.5 \%, 2.5 \%$, and $2.7 \%$, respectively. During unloading, the strain recoveries of $27.9 \mathrm{Nb}$ and $28.7 \mathrm{Nb}$ are almost $0 \%$ up to a strain of $1.5 \%$. During the second or more loading-unloading cycle, the stress level at the first transition point of the gradient of stress-strain curve (the point of appearance of the stress-induced martensite phase) increases with the $\mathrm{Nb}$ content although the shapes of stress-strain curves of $27.2 \mathrm{Nb}, 27.9 \mathrm{Nb}$, and $28.7 \mathrm{Nb}$ are slightly different with $\mathrm{Nb}$ content, where the deformation mode may be change according to the volume fraction of the stress induced martensite phase. In the case of $30.3 \mathrm{Nb}$, increase in stress with strain in the elastic deformation region as well as stress recovery occurs in a nonlinear manner, and no stress hysteresis is observed. Therefore, the elastic deformation behavior of $30.3 \mathrm{Nb}$ does not obey Hook's law. The maximum elastic strain observed for $30.3 \mathrm{Nb}$ is $2.3 \%$. During unloading, the residual strain in this case is almost $0 \%$ up to a strain of $1.5 \%$. In the case of $31.0 \mathrm{Nb}$, the stress increases linearly with

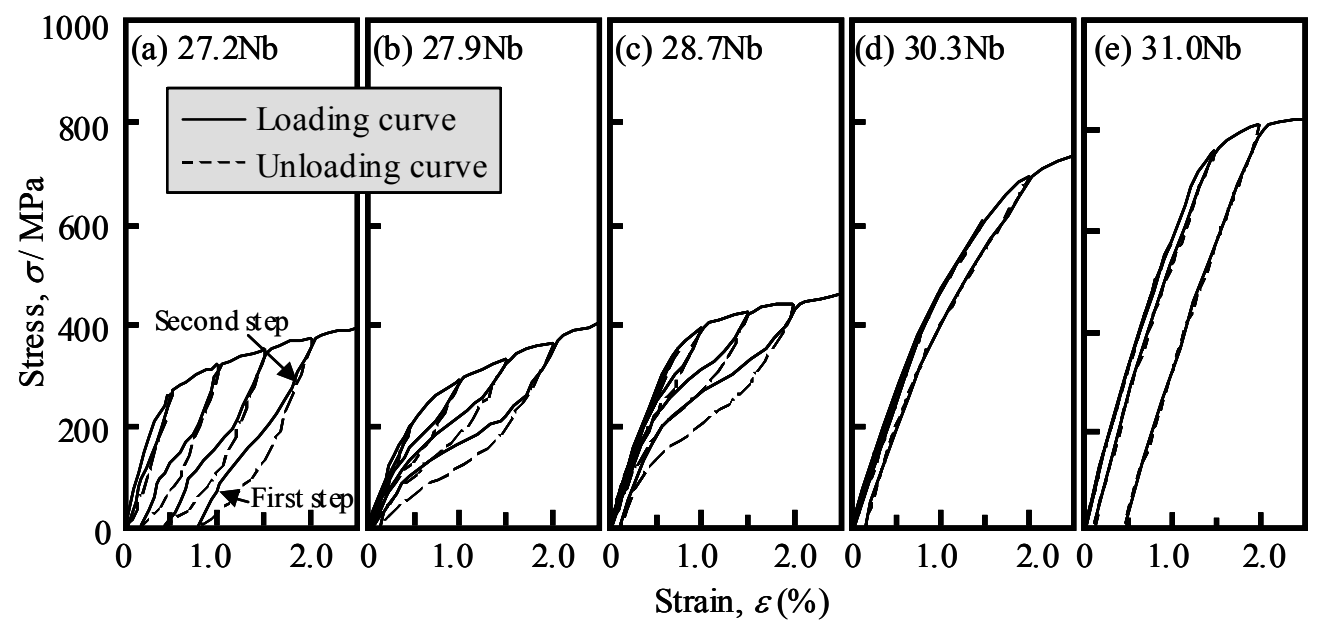

Fig. 4 Tensile stress-strain curves of (a) $27.2 \mathrm{Nb}$, (b) $27.9 \mathrm{Nb}$, (c) $28.7 \mathrm{Nb}$, (d) $30.3 \mathrm{Nb}$ and (e) $31.0 \mathrm{Nb}$ at $300 \mathrm{~K}$. 
strain and shows residual strain even after the first unloading. A residual strain of approximately $1.5 \%$ is observed after unloading. The strain remains nearly constant with an increase in the strain. The maximum elastic strain observed for $31.0 \mathrm{Nb}$ is $1.5 \%$.

In general, the deformation mechanism of the $\beta$ phase changes with its stability ${ }^{(8)-(11)}$. The three main deformation mechanisms of the $\beta$ phase are slip, twining, and stress-induced martensite transformation. The shapes of the stress-strain curves of the Ti-XNb-10Ta-5Zr alloys drastically change with the $\mathrm{Nb}$ content. The shapes of the loading-unloading tensile stress-strain curves of $27.2 \mathrm{Nb}, 27.7 \mathrm{Nb}$, and $28.7 \mathrm{Nb}$ (Fig. 4 (a), (b) and (c)) during the first unloading and second loading are similar to those observed in the metastable $\beta$-type titanium alloys, where stress-induced martensite transformation occurs ${ }^{(12)-(14)}$. The shapes of the loading-unloading tensile stress-strain curves indicate that stress-induced martensite and its reversion occur in $27.2 \mathrm{Nb}, 27.7 \mathrm{Nb}$, and $28.7 \mathrm{Nb}$. On the other hand, the shape memory and superelasticity performances of $\beta$-type titanium alloys are affected by their textures; for example, the $\{001\}<110>$ phase is developed after rolling, while the $\{112\}<110>$ phase is developed after rolling and subsequent crystallization ${ }^{(15)}$. In particular, the direction of superelasticity performance is improved by a well-developed $\{112\}<110>$ crystallization texture parallel to the rolling direction. This is possibly due to the effect of the developed texture on the change in the elastic deformation behavior of the aforementioned alloys, because $\mathrm{Ti}-\mathrm{XNb}-10 \mathrm{Ta}-5 \mathrm{Zr}$ alloys are also cold-rolled at a reduction ratio of around $85 \%$ and then subjected to recrystallization treatment. This possibility needs to be investigated in more detail.

\subsection{XRD Profiles Under Loading and Unloading Conditions}

Figure 5 shows the XRD profiles of $27.2 \mathrm{Nb}$ under various loading and unloading conditions. Peaks due to the $\alpha$ " phase appear at a strain of $1.5 \%$ and do not disappear during

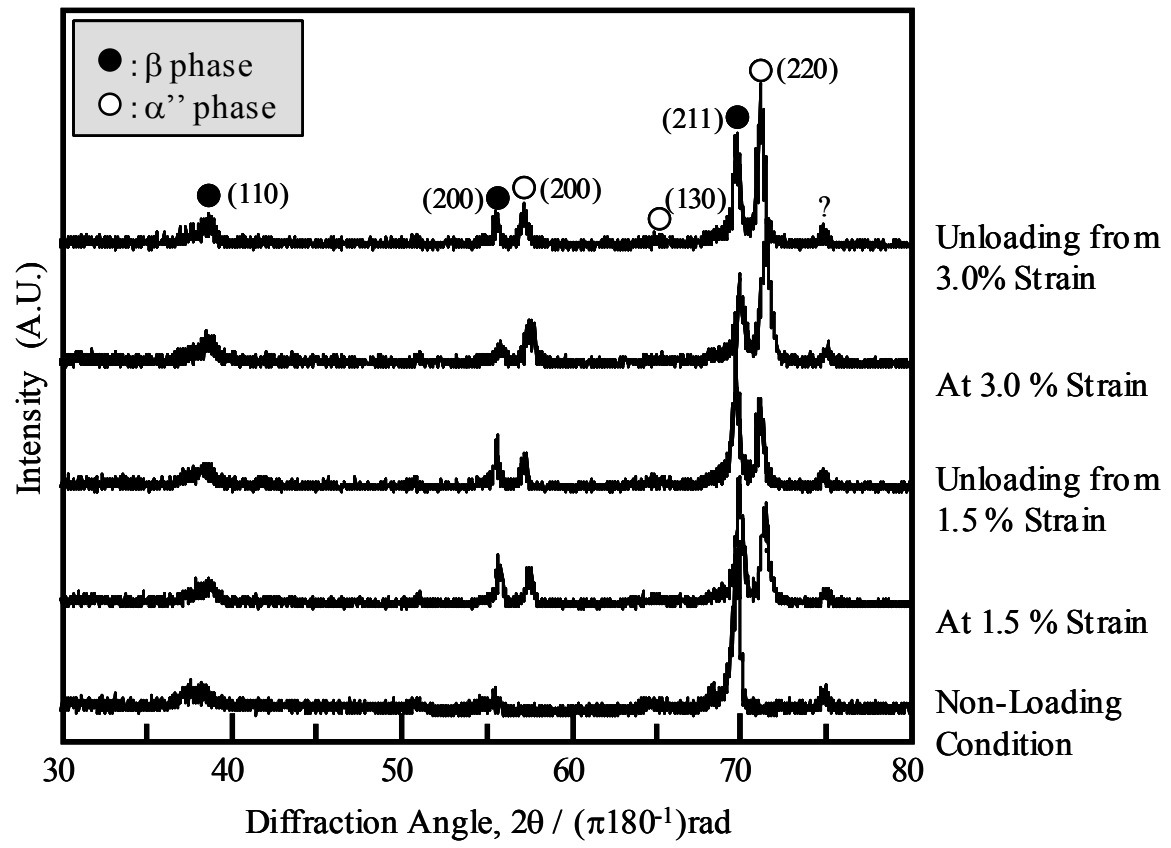

Fig. 5 XRD profiles of $27.2 \mathrm{Nb}$ under various loading conditions at $300 \mathrm{~K}$.

unloading, except at $75^{\circ}$. Therefore, the mechanism of elastic deformation in $27.2 \mathrm{Nb}$ involves stress-induced martensitic transformation and its reversion; however, reverse transformation is considered to occur only to a small degree.

Figure 6 shows the XRD profiles of $27.9 \mathrm{Nb}$ under various loading and unloading conditions. Peaks due to the $\alpha$ " phase appear at strains of $1.5 \%$ and $3.0 \%$ in the elastic 


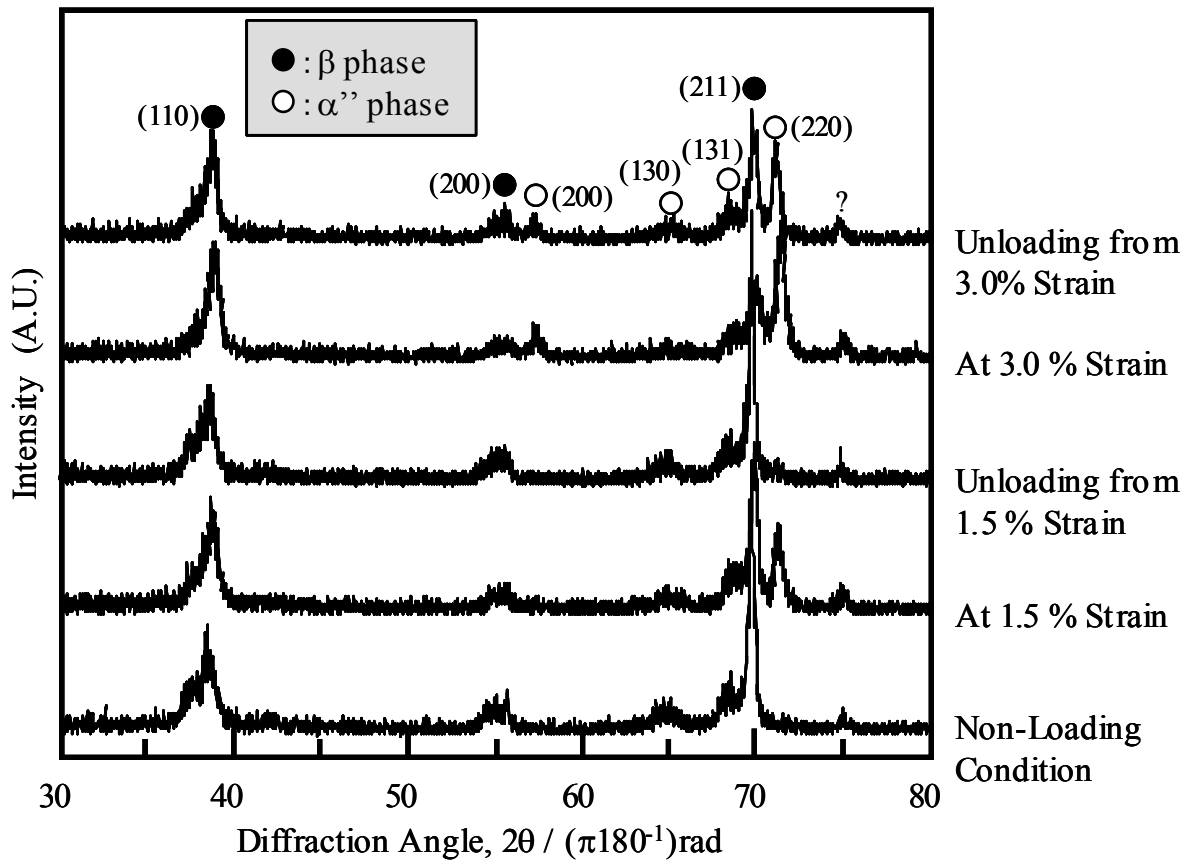

Fig. 6 XRD profiles of $27.9 \mathrm{Nb}$ under various loading conditions at $300 \mathrm{~K}$.

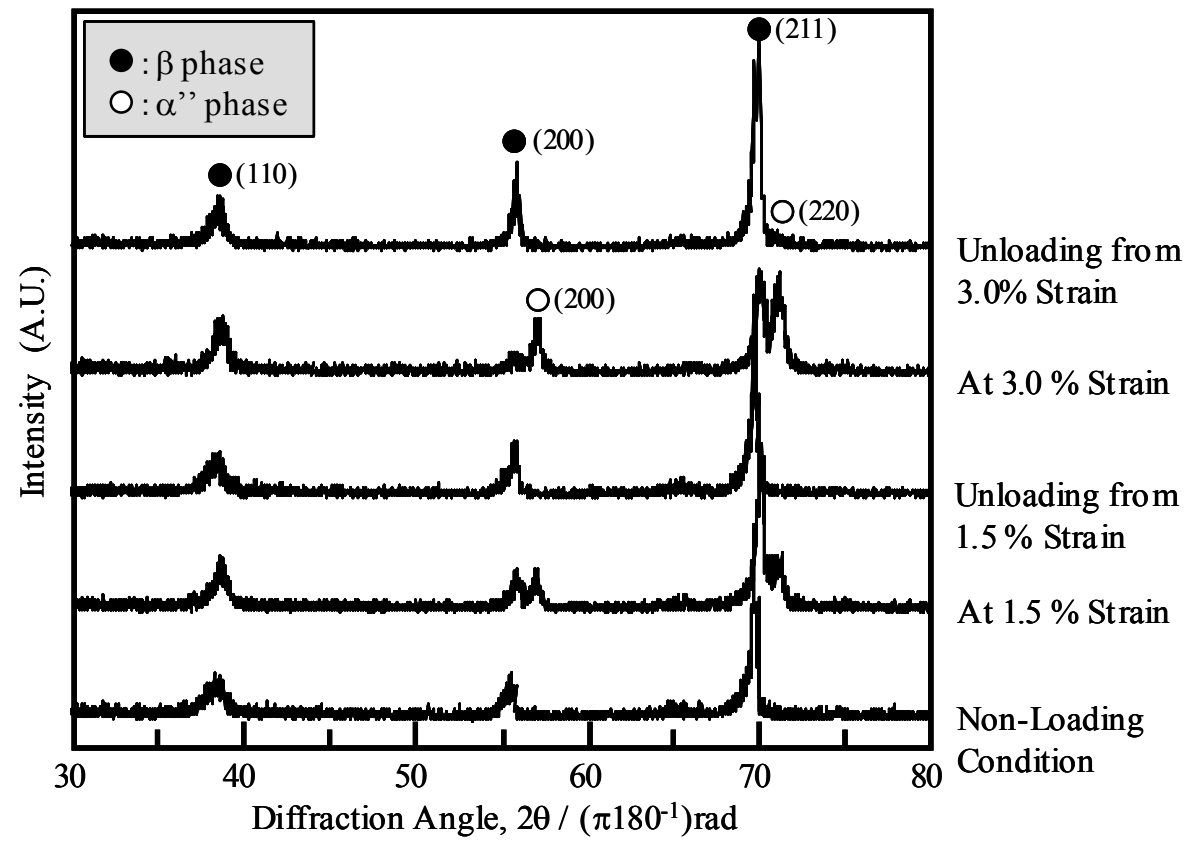

Fig. $7 \mathrm{XRD}$ profiles of $28.7 \mathrm{Nb}$ under various loading conditions at $300 \mathrm{~K}$.

deformation region under the given loading conditions and disappear during unloading at a strain of $1.5 \%$ but not at a strain of $3.0 \%$; this particular behavior is not observed at $75^{\circ}$. Therefore, it can be said that the elastic deformation behavior of $27.9 \mathrm{Nb}$ is also due to stress-induced martensitic transformation and its reversion. However, the reversion of the abovementioned martensitic transformation in $27.9 \mathrm{Nb}$ is different from the reversion observed in $27.2 \mathrm{Nb}$. In the case of $27.9 \mathrm{Nb}$, the peak due to the $\alpha$ " phase exists at $75^{\circ}$ even under the given unloading conditions; however, this peak is not detected during the XRD analysis of the plate specimen.

Figure 7 shows the XRD diffraction profiles of $28.7 \mathrm{Nb}$. Peaks due to the $\alpha$ " phase appear at $1.5 \%$ and $3.0 \%$ strain in the deformation region during loading and disappear during 


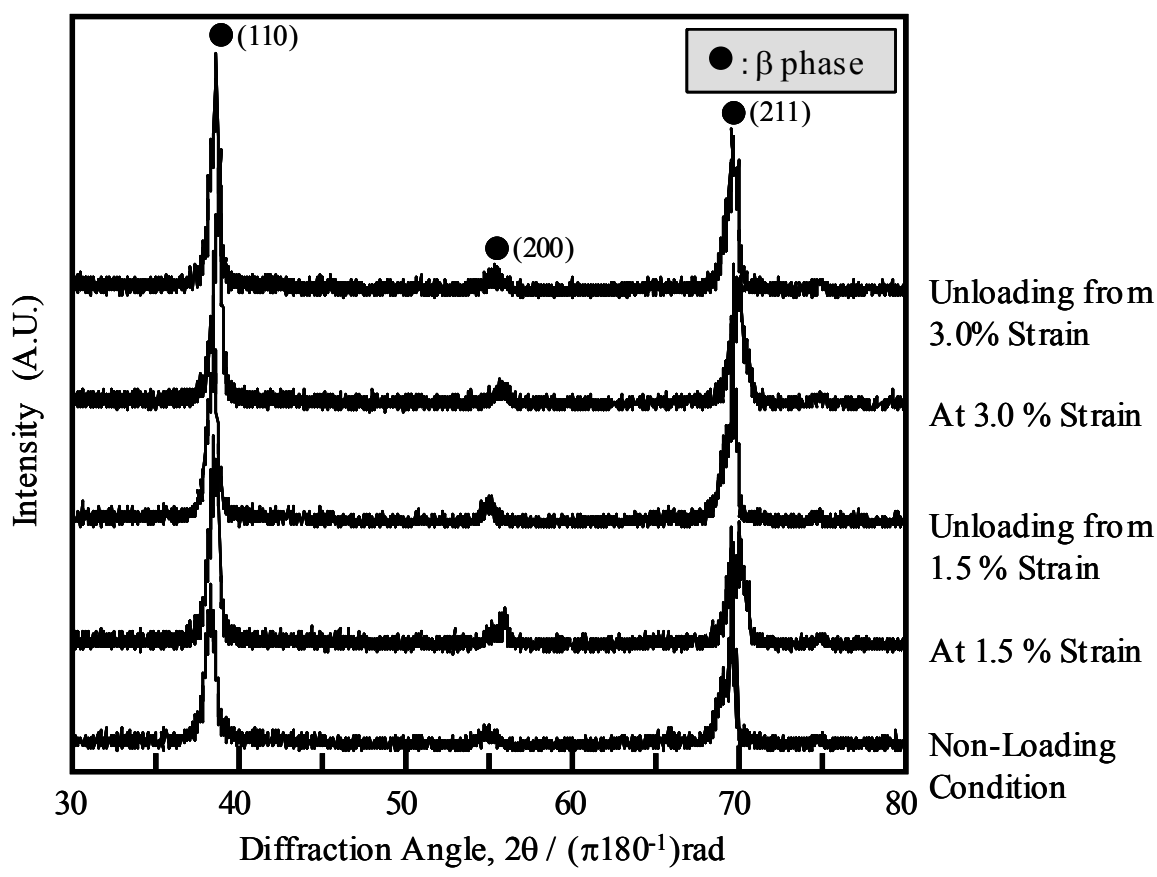

Fig. 8 XRD profiles of $30.3 \mathrm{Nb}$ under various loading conditions at $300 \mathrm{~K}$.

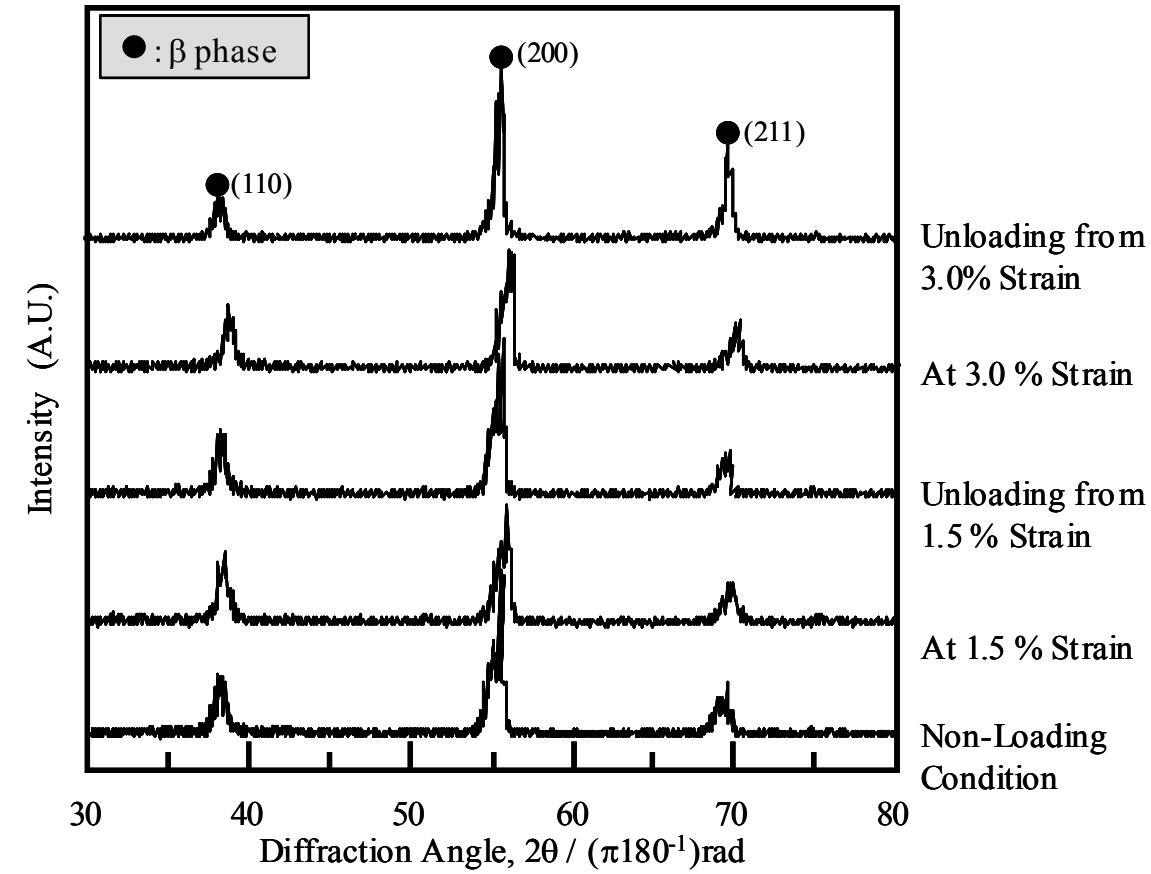

Fig. 9 XRD profiles of $31.0 \mathrm{Nb}$ under various loading conditions at $300 \mathrm{~K}$.

unloading. Therefore, the elastic deformation behavior of $28.7 \mathrm{Nb}$ is considered to be due to stress-induced martensitic transformation and its reversion.

Figures 8 and 9 show the XRD profiles of $31.0 \mathrm{Nb}$ and $30.3 \mathrm{Nb}$, respectively, under various loading and unloading conditions. Only peaks due to the $\beta$ phase are observed under the given loading and unloading conditions. The peaks due to the $\beta$ phase shift to the high-angle region during loading rather than during unloading. Therefore, the elastic deformations in $31.0 \mathrm{Nb}$ and $30.3 \mathrm{Nb}$ can not conclude to be due to the stress-induced martensitic transformation and its reversion in the present state. In the case of $30.3 \mathrm{Nb}$ and $31.0 \mathrm{Nb}$, the microstructures obtained from the tensile loading-unloading tests reveal the presence of a single phase, i.e., the $\beta$ phase, as shown in Fig. 10; in contrast, it is confirmed that the microstructures of $27.2 \mathrm{Nb}, 27.7 \mathrm{Nb}$, and $28.7 \mathrm{Nb}$ contain the stress-induced 


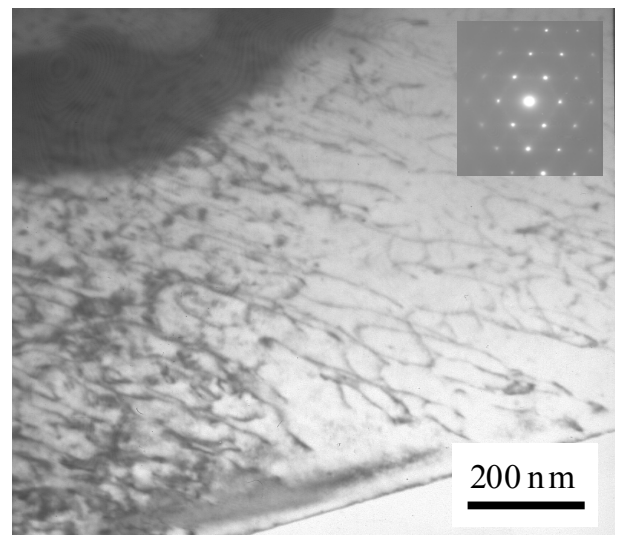

(a) $30.3 \mathrm{Nb}$

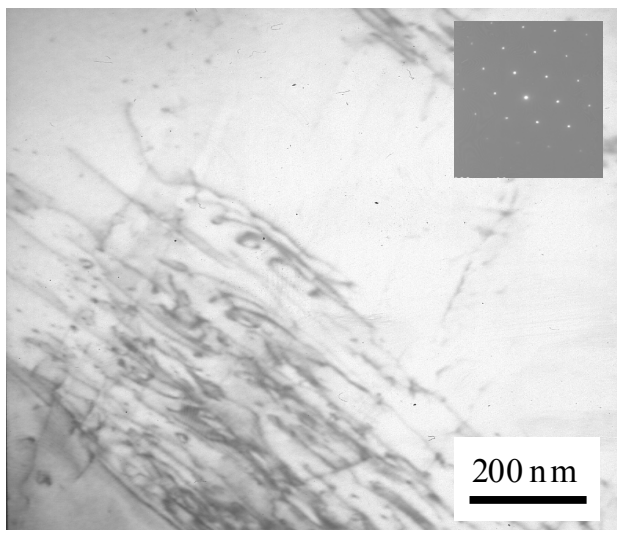

(b) $31.0 \mathrm{Nb}$

Fig. 10 Bright field images and diffraction patterns of (a) $30.3 \mathrm{Nb}$ and (b) $31.0 \mathrm{Nb}$ after tensile tests. Beam direction is para llel to [111].

martensite phase. However, it needs further investigation because there is a possibility of the reverse transformation of martensite.

\subsection{Change in Elastic Deformation Behavior and XRD profiles at Low Temperatures}

The tensile loading-unloading stress-strain curves of $28.7 \mathrm{Nb}$ and $30.1 \mathrm{Nb}$ at $213 \mathrm{~K}$ and $253 \mathrm{~K}$ are shown in Fig. 11. The stress-strain curve of $28.7 \mathrm{Nb}$ exhibits typical stress hysteresis during loading and unloading at $213 \mathrm{~K}$ and $253 \mathrm{~K}$. The strain in this specimen is recovered to almost $0 \%$ up to a strain of $1.5 \%$ during unloading at $253 \mathrm{~K}$ nearly equal to during unloading at $300 \mathrm{~K}$, as shown in Fig. 4(c); however, a residual strain of around $0.1 \%$ is observed at $213 \mathrm{~K}$. This is thought to be due to the partial transformation of the $\alpha$ " phase, as the martensite start temperature is close to $213 \mathrm{~K}$ in the case of $28.7 \mathrm{Nb}$. The stress-strain curve of $30.1 \mathrm{Nb}$ shows a slight stress hysteresis during loading and unloading at $213 \mathrm{~K}$; on the other hand, at $253 \mathrm{~K}$, a nonlinear increase in stress with strain in the elastic deformation region occurs along with stress recovery, and no stress hysteresis is observed here. The strain in $30.1 \mathrm{Nb}$ is recovered to almost $0 \%$ up to a strain of $1.5 \%$ during unloading at $213 \mathrm{~K}$ and $253 \mathrm{~K}$ than during unloading at $300 \mathrm{~K}$, as can be seen in Fig. 4(d). From these results, it is considered that the martensite start temperature in $30.1 \mathrm{Nb}$ is below $213 \mathrm{~K}$. However, the decrease in the martensite start temperature of $\mathrm{Ti}-\mathrm{Nb}$ alloys at around $40 \mathrm{~K} / \mathrm{mass} \%{ }^{(16)}$ suggests that the martensite start temperature of $30.1 \mathrm{Nb}$ is probably below $150 \mathrm{~K}$. Figure 12 shows the XRD profiles of $28.7 \mathrm{Nb}$ and $30.1 \mathrm{Nb}$ at $300 \mathrm{~K}, 143 \mathrm{~K}$, and $93 \mathrm{~K}$. In the XRD

(a) $28.7 \mathrm{Nb}$

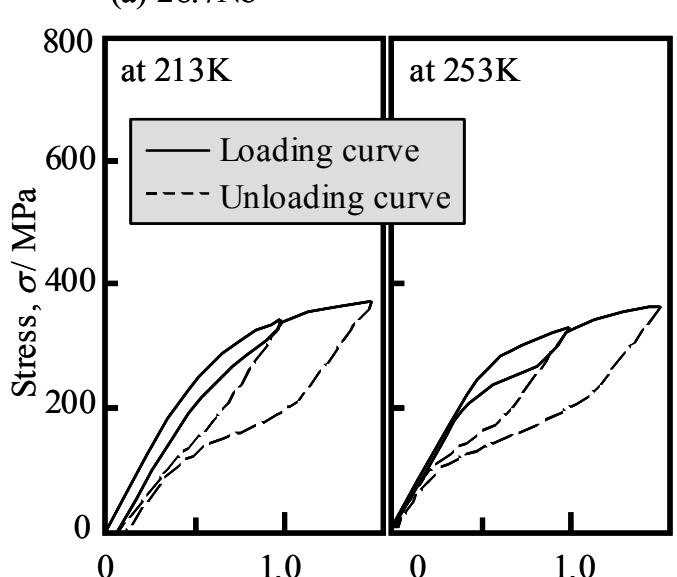

(b) $30.1 \mathrm{Nb}$

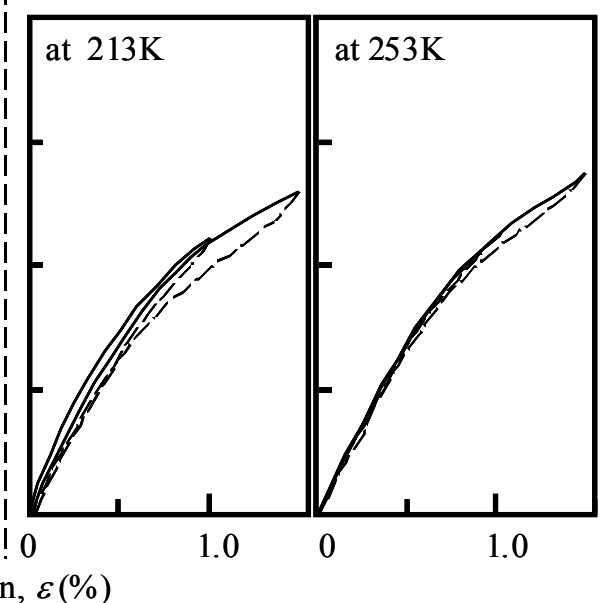

Fig. 11 Tensile loading-unloading stress-strain curves of (a) $28.7 \mathrm{Nb}$ and (b) $30.1 \mathrm{Nb}$ at $213 \mathrm{~K}$ and $253 \mathrm{~K}$. 


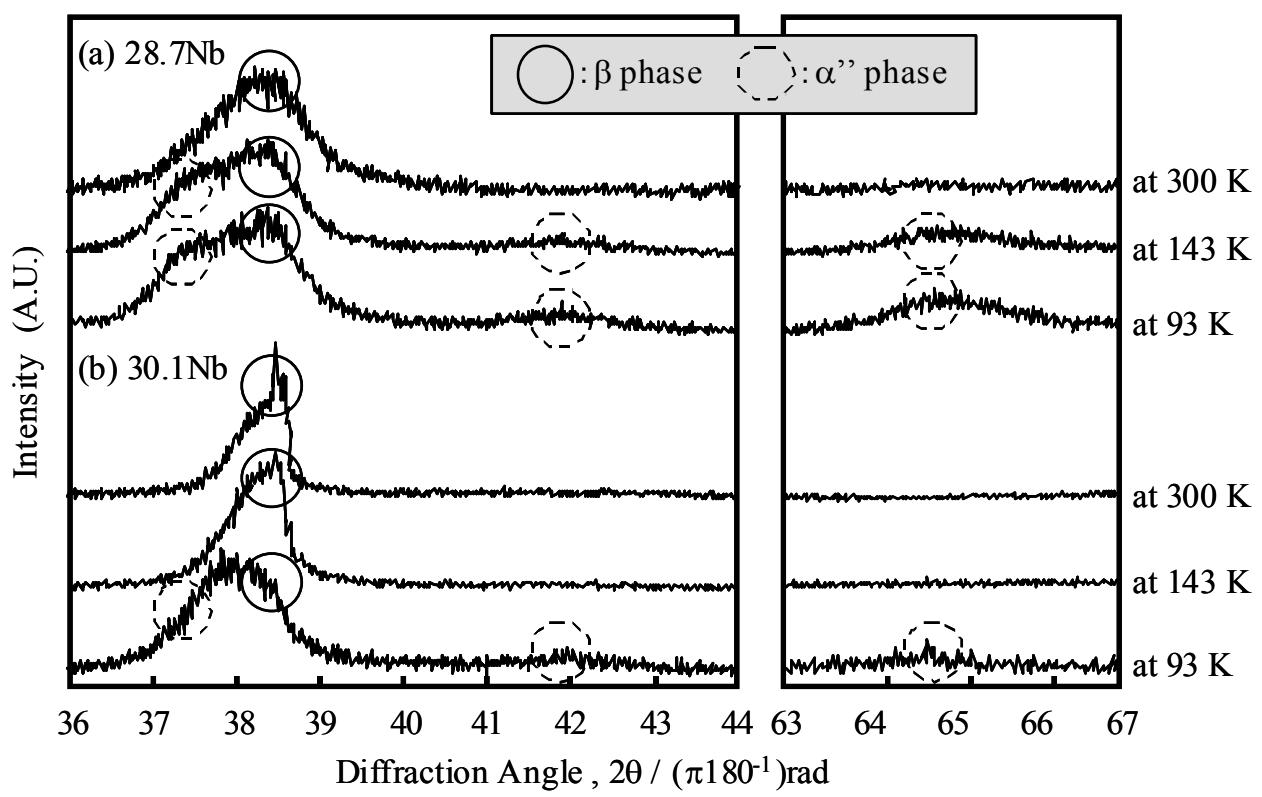

Fig. $12 \mathrm{XRD}$ profiles of (a) $28.7 \mathrm{Nb}$ and (b) $30.1 \mathrm{Nb}$ at $93 \mathrm{~K}, 143 \mathrm{~K}$ and $300 \mathrm{~K}$.

profile of $28.7 \mathrm{Nb}$, some weak and broad peaks due to the $\alpha$ " phase are confirmed in the diffraction angle ranges of $37^{\circ}-38^{\circ}, 41^{\circ}-43^{\circ}$, and $64^{\circ}-66^{\circ}$ at $93 \mathrm{~K}$ and $143 \mathrm{~K}$ along with the peaks due to the $\beta$ phase; however, at $300 \mathrm{~K}$, only peaks due to the $\beta$ phase are observed. In the case of $30.1 \mathrm{Nb}$, at $93 \mathrm{~K}$, very weak peaks due to the $\alpha$ " phase are observed along with the peaks due to the $\beta$ phase. The martensite start temperature in this alloy is between $93 \mathrm{~K}$ and $143 \mathrm{~K}$. Thus, this result is consistent with the predicted martensite start temperature mentioned previously $(<150 \mathrm{~K})$. However, this aspect needs to be confirmed through further investigation because of the very small intensity of the $\alpha$ " phase peaks observed below the martensite start temperature in the XRD profile of $30.1 \mathrm{Nb}$.

\section{Summary}

In this study, changes in superelasticity of the Ti-30Nb-10Ta-5Zr alloy (TNTZ) in which the $\mathrm{Nb}$ content was altered between 1.0 and $3.0 \mathrm{mass} \%$ from $30 \mathrm{mass} \%$ were investigated by tensile loading-unloading tests, XRD analysis, and microstructural analysis using a TEM. The following results were obtained:

(1) When the $\mathrm{Nb}$ content is less than approximately 29 mass $\%$, the tensile loading-unloading stress-strain curves are similar to those representing the general shape-memory behavior, which occurs due to stress-induced martensitic transformation and its reversion.

(2) When the $\mathrm{Nb}$ content is approximately $30 \mathrm{mass} \%$, the tensile loading-unloading curves exhibit superelastic behavior, which cannot be explained on the basis of stress-induced martensitic transformation and its reversion in the present state.

(3) When the $\mathrm{Nb}$ content is approximately 31 mass $\%$, the tensile loading-unloading curves show a single gradient. The elastic deformation is mainly caused by the elastic strain in the lattice.

(4) Changes in the chemical content of Nb in TNTZ within a very narrow range can alter the superelastic behavior of this alloy.

\section{Acknowledgements}

The authors would like to thank Daido Steel Co., Ltd. (Nagoya, Japan), for their assistance in preparing the materials used in this research. This study was supported in part by the Global COE Program "Materials Integration International Center of Education and 
Research, Tohoku University", Ministry of Education, Culture, Sports, Science and Technology (MEXT) (Tokyo, Japan) and The New Energy and Industrial Technology Development Organization (NEDO) (Tokyo, Japan), the collaborative project between Tohoku University and Kyusyu University on "Highly-functional Interface Science: Innovation of Biomaterials with Highly-functional Interface to Host and Parasite", MEXT (Tokyo, Japan), The Light Metal Educational Foundation, Inc. (Osaka, Japan), the cooperative research program of Institute for Materials Research, Tohoku University (Sendai, Japan), and the cooperative research program of the Advanced Research Center of Metallic Glasses, Institute for Materials Research, Tohoku University (Sendai, Japan).

\section{References}

(1) M. Niinomi, Biomaterials 24 (2003), pp. 2673-2683.

(2) T. Akahori, M. Niinomi, H. Fukui, A. Suzuki, Mater. Trans. 45 (2004) 1540-1548.

(3) M. Niinomi, K. Morikawa, T. Kasuga, A. Suzuki, H. Fukui, S. Niwa, Mater. Trans. 43 (2002), pp. 2970-2979.

(4) M. Niinomi, Mater. Trans. 49(2008), pp. 2170-2178.

(5) N. Sakaguchi, M. Niinomi, T. Akahori, J. Takeda and H. Toda, J. Japan Inst. Metals, 68(2004), pp. 1076-1082.

(6) M. Niinomi, T. Akahori, S. Katsura, K. Yamaguchi and M. Ogawa: Mater. Sci. Eng. C, 27(2007), pp. 154-161.

(7) S. Hanada, T. Yoshito and O. Izumi, J. Japan Inst. Metals, 23(1982), pp. 507-517.

(8) T. Grosdidier, M. J. Philippe, Mater. Sci. Eng. A291 (2000), pp. 218-223.

(9) T. Grosdidier, Y. Combres, E. Gautier, M. J. Philippe, Metall. Mater. Trans. 31A (2000), pp. 1095-1106.

(10) S. Hanada, M. Ozeki, O. Izumi, Metall. Trans. 16A (1985), pp. 789-795.

(11) O. P. Karasevskaya, O. M. Ivasishin, S. L. Semiatin, Y. V. Matviychuk, Mater. Sci. Eng. A354 (2003), pp. 121-132.

(12) T. Grosdidier, M. J. Philippe, Mater. Sci. Eng. A291 (2000) 218-223.

(13) T. Grosdidier, Y. Combres, E. Gautier, M. J. Philippe, Metall. Mater. Trans. 31A (2000), pp. 1095-1106.

(14) X. L. Meng, W. Cai, Y. F. Zheng, Y. X. Tong, L. C. Zhao, L. M. Zhou, Mater. Letters 55 (2002), pp. 111-115.

(15) H. Y. Kim, T. Sasaki, K. Okutsu, J. I. Kim, T. Inamura, H. Hosoda and S. Miyazaki, Acta Materialia, 54(2006), pp. 423-433.

(16) H. Kim, H. Hosoda and S. Miyazaki, J. Japan inst. Light Metals, 55(2005), pp. 613-617. 